\title{
Use of Marginal Organs in Kidney Transplantation for Marginal Recipients: Too Close to the Margins of Safety?
}

\author{
M. Heuer ${ }^{1}$, A. Zeiger ${ }^{1}$, G. M. Kaiser ${ }^{1}$, Z. Mathé ${ }^{1}$, A. Goldenberg ${ }^{1}$, S. Sauerland ${ }^{2}$, A. Paul ${ }^{1}$, \\ J. W. Treckmann ${ }^{1}$ \\ ${ }^{1}$ Department of General-, Visceral- and Transplantation Surgery, University Hospital of Essen, Germany,
2Institute for Research in Operative Medicine, University of Witten/Herdecke, Cologne, Germany
}

\begin{abstract}
Objective: Due to organ shortage, average waiting time for a kidney in Germany is about 4 years after start of dialysis. Number of kidney grafts recovered can only be maintained by accepting older and expanded criteria donors. The aim of this study was to analyse the impact of donor and recipient risk on kidney longterm function.

Methods: All deceased kidney transplantations were considered. We retrospectively studied 332 patients between 2002 and 2006; divided in 4 groups reflecting donor and recipient risk.

Results: Non-marginal recipients were less likely to receive a marginal organ (69 of 207, 33\%) as compared to marginal recipients, of whom two-thirds received a marginal organ $(p<0.0001)$. Graft function significantly differed between the groups, but detrimental effect of marginal recipient status on eGFR after 12 months $(-6 \mathrm{ml} / \mathrm{min} / 1.73 \mathrm{qm}, 95 \%$ CI -2 to -9$)$ was clearly smaller than the effect of marginal donor status $(-10$ $\mathrm{ml} / \mathrm{min} / 1.73 \mathrm{qm}, 95 \% \mathrm{CI}-7$ to -14$)$.

Conclusions: As we were able to show expanded criteria donor has a far bigger effect on long-term graft function than the "extra risk" recipient. Although there have been attempts to define groups of recipients who should be offered ECD kidneys primarily the discussion is still ongoing.
\end{abstract}

Key words: Expanded criteria donors, kidney transplantation, marginal donors, marginal recipients, outcome, prognosis

\section{INTRODUCTION}

Since renal transplantation is increasingly successful, also older patients and patients with relevant co-morbidities are more frequently accepted on the waiting list, aggravating the persisting discrepancy between the number of patients on the waiting list and organs available [1]. Beside this the absolute number of grafts recovered can only be maintained by accepting older donors and donors with characteristics potentially causing poorer short- and long-term outcome of kidney transplantation [2]. The quality of the donor organ is one of the strongest parameters for prediction of graft survival [3, 4]. Nevertheless, it has been shown that recipients of kidneys of marginal donors or expanded criteria donors have a benefit of extra-life years compared to wait-listed dialysis patients, despite decreased long-term graft function [5].

The aim of this study was to analyse the impact of donor and recipient on kidney function after transplantation and especially whether the converging of "extra risk" recipients (i.e. with relevant co-morbidity) and marginal donors bears an additional risk compared to other risk constellations.

\section{Methods and Statistics}

Definitions: According to the UNOS definition an expanded criteria donor was defined as a donor older than 60 years or older than 50 years with at least two of the following three criteria: creatinine $>1.5 \mathrm{mg} / \mathrm{dl}$, history of hypertension, CVA as cause of death.

„Extra risk“ recipients were defined as recipients older than 60 years or older than 50 years with at least one of the following risk factors: coronary heart disease, peripheral arterial disease (PAD, grade IIa or higher), diabetes mellitus.

Study Sample: We studied a registry of consecutive deceased renal transplantations performed in the University Hospital of Essen, Germany between 2002 and 2006 ( $\mathrm{n}=332$ ). There were 138 patients in group 1 (donor and recipient no extra risk), 41 in group 2 (donor non-marginal, extra risk recipient), 69 in group 3 (donor marginal, recipient non extra risk), and 84 in group 4 (donor marginal, extra risk recipient).

Measurements: Estimated glomerular filtration rate (eGFR) was calculated using the MDRD formula: eGFR $\left(\mathrm{ml} / \mathrm{min} / 1.73 \mathrm{~m}^{2}\right)=186 \times \mathrm{CrS}^{-1.154} \mathrm{x}^{2} \mathrm{age}^{-0.203} \mathrm{x}$ 0.742 (if female).

Statistical Analysis: Graft loss, delayed graft function and eGFR were compared between the groups by univariate and multivariate statistics. We used a generalized linear model to statistically test the influence of donor and recipient characteristics on postoperative eGFR values. This way of analysis accounts for the dependency among the time points. In case of violation of the sphericity assumption, the GreenhouseGeisser correction was employed. An interaction term (donor status; recipient status) was included to answer 
Table 1. Baseline characteristics of the four groups.

\begin{tabular}{|c|c|c|c|c|c|}
\hline & $\begin{array}{l}\text { Group 1: } \\
\text { Donor and } \\
\text { recipient } \\
\text { non- } \\
\text { marginal }\end{array}$ & $\begin{array}{l}\text { Group 2: } \\
\text { Donor non- } \\
\text { marginal, } \\
\text { recipient } \\
\text { marginal }\end{array}$ & $\begin{array}{l}\text { Group 3: } \\
\text { Donor } \\
\text { marginal, } \\
\text { recipient } \\
\text { non- } \\
\text { marginal }\end{array}$ & $\begin{array}{l}\text { Group 4: } \\
\text { Donor and } \\
\text { recipient } \\
\text { marginal }\end{array}$ & P-value \\
\hline No. of patients & 138 & 41 & 69 & 84 & - \\
\hline Females $(\%)$ & $55(39.9 \%)$ & $20(48.8 \%)$ & $30(43.5 \%)$ & $28(33.3 \%)$ & 0.359 \\
\hline Recipient age (years) & $42.7 \pm 10.4$ & $61.8 \pm 5.0$ & $42.7 \pm 10.1$ & $64.5 \pm 5.1$ & $<0.001$ \\
\hline Recipient body mass index $\left(\mathrm{kg} / \mathrm{m}^{2}\right)$ & $24.7 \pm 4.6$ & $25.5 \pm 4.0$ & $23.9 \pm 3.5$ & $25.4 \pm 3.8$ & 0.102 \\
\hline \multicolumn{6}{|l|}{ Recipient comorbidity } \\
\hline Arterial hypertension & $14(10 \%)$ & $5(12 \%)$ & $9(13 \%)$ & $4(5 \%)$ & 0.325 \\
\hline Arteriosclerotic disease & $15(11 \%)$ & $19(46 \%)$ & $7(10 \%)$ & $26(31 \%)$ & $<0.001$ \\
\hline Heart insufficiency & $10(7 \%)$ & $4(10 \%)$ & $2(3 \%)$ & $8(10 \%)$ & 0.387 \\
\hline Diabetes mellitus & $11(8 \%)$ & $14(34 \%)$ & $3(4 \%)$ & $15(18 \%)$ & $<0.001$ \\
\hline Thyroid disease & $9(7 \%)$ & $2(5 \%)$ & $7(11 \%)$ & $9(11 \%)$ & 0.528 \\
\hline Secondary hyperparathyreoidism & $91(66 \%)$ & $24(60 \%)$ & $44(66 \%)$ & $54(68 \%)$ & 0.907 \\
\hline Tertiary hyperparathyreoidism & $8(6 \%)$ & $3(8 \%)$ & $4(6 \%)$ & $2(3 \%)$ & 0.907 \\
\hline Hypercholesterolemia & $18(13 \%)$ & $8(20 \%)$ & $14(20 \%)$ & $33(40 \%)$ & $<0.001$ \\
\hline Chronic obstructive lung disease & $8(6 \%)$ & $2(5 \%)$ & $2(3 \%)$ & $5(6 \%)$ & 0.808 \\
\hline Duration of dialysis (months) & $72(42)$ & $67(36)$ & $86(55)$ & $63(35)$ & 0.007 \\
\hline First transplantation & $101(73 \%)$ & $34(83 \%)$ & $50(73 \%)$ & $66(79 \%)$ & 0.802 \\
\hline \multirow[t]{3}{*}{ HLA-DR mismatches $(0 / 1 / 2)$} & $46(33 \%)$ & $14(34 \%)$ & $26(38 \%)$ & $18(21 \%)$ & \\
\hline & $60(43 \%)$ & $15(37 \%)$ & $28(41 \%)$ & $32(38 \%)$ & 0.083 \\
\hline & $32(23 \%)$ & $12(29 \%)$ & $15(22 \%)$ & $34(41 \%)$ & \\
\hline Same gender transplantation & $60(44 \%)$ & $21(51 \%)$ & $35(53 \%)$ & $47(56 \%)$ & 0.571 \\
\hline
\end{tabular}

Table 2. Clinical results in the four groups.

\begin{tabular}{|c|c|c|c|c|c|}
\hline & $\begin{array}{l}\text { Group 1: } \\
\text { Donor and } \\
\text { recipient } \\
\text { non- } \\
\text { marginal }\end{array}$ & $\begin{array}{l}\text { Group 2: } \\
\text { Donor non- } \\
\text { marginal, } \\
\text { recipient } \\
\text { marginal }\end{array}$ & $\begin{array}{l}\text { Group 3: } \\
\text { Donor } \\
\text { marginal, } \\
\text { recipient } \\
\text { non- } \\
\text { marginal }\end{array}$ & $\begin{array}{l}\text { Group 4: } \\
\text { Donor and } \\
\text { recipient } \\
\text { marginal }\end{array}$ & P-value \\
\hline No. of patients & 138 & 41 & 69 & 84 & - \\
\hline Duration of surgery (minutes) & $159 \pm 63$ & $164 \pm 63$ & $153 \pm 41$ & $173 \pm 71$ & 0.358 \\
\hline \multicolumn{6}{|l|}{ Immunosuppression } \\
\hline Mycophenolate mofetil (Cell Cept) & $101(73 \%)$ & $24(59 \%)$ & $44(64 \%)$ & $53(63 \%)$ & 0.203 \\
\hline Tacrolimus & $86(62 \%)$ & $22(54 \%)$ & $37(54 \%)$ & $49(58 \%)$ & 0.593 \\
\hline Cyclosporin A & $44(32 \%)$ & $18(44 \%)$ & $25(36 \%)$ & $30(36 \%)$ & 0.559 \\
\hline Sirolimus & $5(4 \%)$ & $1(2 \%)$ & $11(16 \%)$ & $4(5 \%)$ & 0.003 \\
\hline Intensive care stay donor (days) & $6.2 \pm 5.7$ & $6.9 \pm 6.6$ & $6.1 \pm 6.0$ & $3.5 \pm 3.2$ & $0.001 \S$ \\
\hline Hospital stay recipient (days) & $18.0 \pm 14.0$ & $18.9 \pm 14.2$ & $15.7 \pm 11.6$ & $17.7 \pm 19.5$ & 0.699 \\
\hline Any complication * & $48(36 \%)$ & $20(49 \%)$ & $36(52 \%)$ & $36(43 \%)$ & 0.151 \\
\hline Rejection & $38(28 \%)$ & $2(5 \%)$ & $27(39 \%)$ & $26(31 \%)$ & 0.001 \\
\hline Primary non-function requiring dialysis & $50(38 \%)$ & $11(27 \%)$ & $20(29 \%)$ & $32(39 \%)$ & 0.355 \\
\hline Loss of graft & $8(6 \%)$ & $2(5 \%)$ & $7(10 \%)$ & $8(10 \%)$ & 0.539 \\
\hline Death & $3(2 \%)$ & $2(5 \%)$ & $1(1 \%)$ & $6(7 \%)$ & 0.176 \\
\hline
\end{tabular}

* except urinary tract infection; $\int$ additional nonparametric testing yielded a $\mathrm{P}=0.001$ by Kruskal-Wallis test 
Table 3. Results of multivariate regression analyses.

\begin{tabular}{lccc}
\hline & eGFR at 1 week & eGFR at 1 month & eGFR at 12 months \\
\hline Marginal donor & 0.054 & $<0.001$ & $<0.001$ \\
Marginal recipient & 0.852 & 0.611 & 0.153 \\
HLA mismatches & 0.103 & 0.685 & 0.983 \\
Duration of dialysis & 0.416 & 0.658 & 0.571 \\
\hline
\end{tabular}

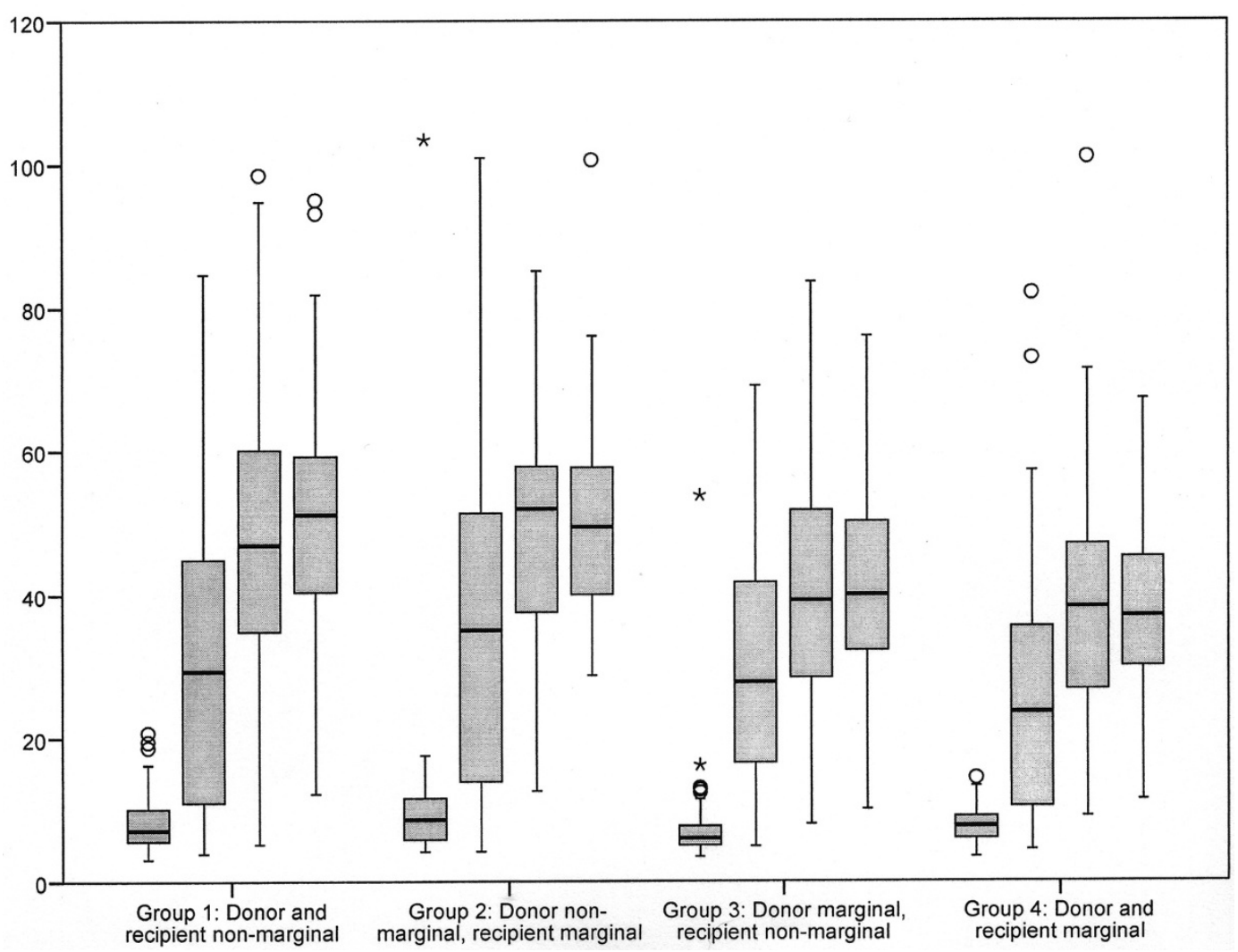

Fig. 1. Recipient eGFR (in $\mathrm{ml} / \mathrm{min} / 1.73 \mathrm{~m}^{2}$ ) at transplantation, and after 1,4 , and 52 weeks in the four groups.

the research question, whether organs from marginal donors are especially detrimental when implanted in marginal recipients. To compare among the groups, we used standard statistical methodology, including ANOVA and chi-square testing. A p-value of less than 0.05 was used to define significance.

\section{RESULTS}

About $75 \%$ of the 332 patients received their first kidney transplantation. The average duration of pretransplant dialysis was 6 years. As expected, marginal recipients were significantly older and more likely to suffer from co-morbidities (Table 1). About half of all patients received their graft from a donor having the same gender. Non-marginal recipients were less likely to receive a marginal organ (69 of $207,33 \%$ ) as compared to marginal recipients, of whom two thirds received a marginal organ $(p<0.0001)$.

Median ICU stay of the donor was 4 days (interquartile range 2 to 8 ) and was significantly shorter in group 4. The rate of delayed graft function defined by necessity of dialysis in the first week after transplantation was $35 \%$, but without difference among the groups. Delayed graft function was slightly more likely to be developed in patients who were on dialysis prior to transplantation for a longer duration (78 vs. 69 months, $\mathrm{p}=0.078$ ) (Table 2).

Graft function significantly differed between the four groups, but the detrimental effect of marginal recipient status on eGFR after 12 months $(-6 \mathrm{ml} / \mathrm{min} /$ $1.73 \mathrm{qm}, 95 \%$ CI -2 to -9$)$ was clearly smaller than the effect of marginal donor status $(-10 \mathrm{ml} / \mathrm{min} / 1.73 \mathrm{qm}$, 95\% CI -7 to -14 ) (Fig. 1). In multivariate analysis, only marginal donor status significantly $(p<0.001)$ affected graft function after 1 and 12 months, Table 3. However, there was a tendency $(p=0.072)$ towards higher eGFR after 1 year in patients without pre-transplant arterial hypertension $(45 \pm 16)$ as opposed to those with hypertensive disease (41 \pm 14 ). Rates of death after one year in the extra risk recipients were higher compared to the other recipients $(6.4 \%$ vs. $1.9 \%)$ but without reaching significance $(\mathrm{p}=0.07)$. 


\section{DISCUSSION}

Clinical reality in kidney transplantation is determined by nearly stable numbers of organ donors with an increment of the relative number of expanded criteria donors. The influence of the quality of donor organs for long-term graft survival has been demonstrated. Although just about $15 \%$ of all patients on dialysis are actually on the waiting lists in the Eurotransplant region, which means that a large number of patients do not qualify for kidney transplantation because of their medical status, the number of older recipients and recipients with relevant co-morbidities seems to increase. We tried to define an extra risk recipient by combination of age and distinct co-morbidities like diabetes, coronary heart disease and PAD, since these influence mortality after kidney transplantation as well as on dialysis. The one year patient survival rate of ECD kidney recipients was $95.4 \%$ thus comparable to UNOS data with one year graft survival rates of $90 \%$ nearly identical to UNOS data [6]. The differences in outcome concerning graft and patient survival compared to non- ECD kidney recipients were not significant in this analysis, but are consistent with UNOS data. Nevertheless, results of ECD and standard donor kidney transplantation cannot be directly compared because age and co-morbidities are not equally distributed between ECD and standard recipients. This analysis stratifies outcome related to donor and recipient risk. As we were able to show the expanded criteria donor has a far bigger effect on longterm graft function than the "extra risk" recipient. Although there have been attempts to define groups of recipients who should be offered ECD kidneys primarily the discussion is still ongoing. In a recent review it was concluded that just patients younger than 40 years scheduled for re-transplantation should not be offered ECD kidneys, since survival for patients older than 40 years receiving an ECD kidney is better than remaining on dialysis [7]. Schold et al. showed that older patients $(65+)$ had a longer life expectancy when transplanted with an ECD kidney within 2 years of ESRD onset compared with waiting on a standard kidney [8]. The duration of pre-transplant dialysis has a significant impact on outcome after transplantation especially including analysis of larger databases which emphasize early transplantation of marginal recipients because of higher risk of mortality on dialysis [9-12]. Since we could show that the efficacy of transplantation of marginal kidneys is similar in younger and non-co-morbid versus older co-morbid patients, we can conclude that the margins of safety are usually not to close, when an ECD kidney is transplanted to an extra risk recipient. Therefore, the advantages of shorter waiting times should be taken actively. Our results and recent reviews suggest that programs conveying short waiting times like the Eurotransplant senior program should be extended from recipients older than 65 years to recipients older than 60 years or even younger [13-15].

\section{REFERENCES}

1. Heuer M, Fruehauf NR, Treckmann JW, Witzke O, Paul A, Kaiser GM. Kidney procurement and transplantation from a surgical perspective. Dtsch Med Wochenschr. 2009 Feb; 134(9): 412-6.
2. Deutsche Stiftung Organtransplantation, Annual Report 2008.

3. Nyberg SL, Matas AJ, Kremers WK, et al. Improved scoring system to assess adult donors for cadaver renal transplantation. Am J Transplant. 2003 Jun; 3(6): 715-21.

4. Schold JD, Kaplan B, Baliga RS, Meier-Kriesche HU. The broad spectrum of quality in deceased donor kidneys. Am J Transplant. 2005 Apr; 5(4Pt 1): 757-65.

5. Ojo AO, Hanson JA, Meier-Kriesche H, et al. Survival in recipients of marginal cadaveric donor kidneys compared with other recipients and wait-listed transplants candidates. J Am Soc Nephrol. 2001 Mar; 12(3): 589-97.

6. Metzger RA, Delmonico FL, Feng S, Port FK, Wynn JJ, Merion RM. Expanded criteria donors for kidney transplantation. Am J Trans. 2003; 3 Supp 4: 114-25.

7. Pascual J, Zamora J, Pirsch JD. A systematic review of kidney transplantation from expanded criteria donors. Am J Kidney Dis. 2008 Sep; 52(3): 553-86.

8. Schold JD, Meier-Kriesche HU. Which renal transplant candidates should accept marginal kidneys in exchange for a shorter waiting time on dialysis? Clin J Am Soc Nephrol. 2006 May; 1(3): 532-8.

9. Sung RS, Guidinger MK, Leichtman AB, et al. Impact of the expanded criteria donor allocation system on candidates for and recipients of expanded criteria donor kidneys. Transplantation. 2007 Nov 15; 84(9): 1138-44.

10. Hattori R, Ohshima S, Ono Y, Fujita T, Kinukawa T, Matsuura O. Long-term outcome of kidney transplants from non-heart-beating donors: multivariate analysis of factors affecting graft survival. Transplant Proc. 1999 Nov; 31(7): 2847-50.

11. Pokorna E, Vitko S, Chadimova M, Schueck O. Factors affecting development of function, level of function, and 36-month graft survival-multivariant analysis. Transplant Proc. 1999 Feb-Mar; 31(1-2): 220-2.

12. Audard V, Matignon M, Dahan K, Lang P, Grimbert P. Renal transplantation from extended criteria cadaveric donors: problems and perspectives overview. Transplant Int. 2008 Jan; 21(1): 11-7.

13. Pascher A, Reutzel-Selke A, Jurisch A, et al. Alterations of the immune response with increasing recipient age are associated with reduced long-term organ graft function of rat kidney allografts. Transplantation. 2003 Dec 15; 76(11): 1560-8.

14. Baskin-Bey ES, Kremers W, Stegall MD, Nyberg SL. United Network for Organ Sharing's expanded criteria donors: is stratification useful? Clin Transplant. 2005 Jun; 19(3): 406-12.

15. Merion RM, Ashby VB, Wolfe RA, et al. Deceased-donor characteristics and the survival benefit of kidney transplantation. JAMA. 2005 Dec 7; 294(21): 2726-33.

Received: August 20, 2009 / Accepted: September 8, 2009

Address for correspondence:

Jürgen W. Treckmann, M.D.

Department of General-,

Visceral- and Transplantation Surgery

University Hospital of Essen

Hufelandstrasse 55, 45122 Essen, Germany

Phone: +49 (201) 72384082

Fax: $\quad+49(201) 7235618$

E-mail: juergen-walter.treckmann@uk-essen.de 